\title{
A ECONOMIA DE JOHN MAYNARD KEYNES: UMA PEQUENA INTRODUÇÃO
}

\author{
Jorge Miguel Cardoso Ribeiro de Jesus'
}

\begin{abstract}
Resumo
O objectivo principal deste artigo é analisar a evolução das ideias e proposições teóricas da obra de John Maynard Keynes. A hipótese primordial deste trabalho, numa abordagem pós-Keynesiana, é a defesa da mudança do pensamento económico de Keynes, de uma visão marshalliana compatível com o capitalismo do laissez - faire, para uma análise teórica inovadora dos problemas do capitalismo pós-grande depressão, nos anos 1930.
\end{abstract}

Palavras-chave: John Maynard Keynes; Teoria geral ; Economia PósKeynesiana.

Classificação JEL: B50; E12; E42; E65; F33.

\section{INTRODUÇÃO}

O objectivo principal deste artigo é analisar a evolução das ideias e proposições teóricas da obra de John Maynard Keynes. A hipótese primordial deste trabalho, numa abordagem pós-Keynesiana, é a defesa da mudança do pensamento económico de Keynes, de uma visão marshalliana compatível com o capitalismo do laissez faire, para uma análise teórica inovadora dos problemas do capitalismo pós-grande depressão, nos anos 1930.

Este artigo, além desta introdução, apresenta as seguintes secções: na primeira, analisam-se a vida e influências filosóficas, sociais e politicas em Keynes; na segunda, examina-se a predominância marshalliana nos primei-

Doutorando em Economia no Departamento de Economia da Universidade de Évora - Portugal. Mestre em Economia pelo Instituto de Economia da UFRJ. Correio: jorgemiguel1987@hotmail.com 
ros anos, na economia de John Maynard Keynes; na terceira, descreve-se a transição na visão económica de Keynes; na quarta, enunciam-se as proposições teóricas inovadoras da Teoria geral; na quinta, aborda-se, muito resumidamente, a aplicação prática da economia de John Maynard Keynes; e, por fim, apresenta-se a conclusão.

\section{VIDA E INFLUÊNCIAS FILOSÓFICAS, SOCIAIS E POLITI- CAS EM KEYNES}

Para Keynes, a economia é essencialmente uma ciência moral e não uma ciência natural, pois lida com a introspecção e com valores (Keynes,CWJMK,XIV,pp.296-297), porque o número de variáveis é grande demais e a estabilidade das mesmas não pode ser garantida(Skidelsky,1999,p.30). Daí a dificuldade de trabalhar com modelos nas relações económicas, logo, para ele, a economia era um ramo da ética e da lógica(Nunes,1998,p.101). Num ensaio sobre Marshall, o economista inglês afirmou que o "mestre economista deve possuir uma rara combinação de atributos ... deve ser matemático, historiador, estadista, filósofo, até certo ponto(Keynes,CWJMK,X,pp.173-174).

As ideias de Keynes estavam enraizadas no tempo e no espaço. Nasceu em 1883 e morreu em 1946. As proposições teóricas de Keynes, foram condicionadas, pela sua função de "policy adviser" do governo inglês, em assuntos económicos, e pela mudança no seu pensamento económico, de uma visão marshalliana compatível com o capitalismo do laissez-faire, para uma análise teórica inovadora dos problemas do capitalismo pós-grande depressão, nos anos 1930(Filho,2006).

A respeito da juventude, influenciado por Moore(1903), Keynes em 1938, escreveu, em "My early beliefs", "Nossos principais objectivos na vida eram o amor, a criação e gozo da experiência estética e a busca do conhecimento. Entre esses, o amor ocupava de longe o primeiro lugar"'(K eynes,CWJMK,X,pp.436-437). Keynes seguiu sempre as "pressuposições de Harved road", em que as reformas e o governo da Grã-Bretanha deveriam estar nas mãos de uma aristocracia intelectual (Harrod,1951).Keynes, tinha uma paixão limitada pela reforma social, pois, esta retirava do mundo maus estados de coisas, o que podia diminuir o total de bondade ética, que 
dependia da existência de maus estados de coisas. Seguindo Burke( 1757), Keynes, preferia o bem presente ao futuro, o que iria moldar a sua análise económica de curto prazo; a sua predilecção pela prudência, em vez de regras fixas e o seu comprometimento com a verdade e a crença na possibilidade do juízo racional dos indivíduos.

Keynes relacionou os estudos da economia académica aos problemas administrativos do governo económico, devido, na tradição de Cambridge, ao seu forte compromisso com finalidades sociais, e à sua rejeição ao modelo económico de Laissez-faire (Keynes, CWJMK, IX), defendendo uma administração do capitalismo e uma integração dos processos analítico e estatístico na economia, ressalvando a importância das premissas(hipóteses), na defesa de um argumento(Robinson, 1947).

John Maynard Keynes começou a trabalhar na teoria das probabilidades em 1905, apresentando um trabalho sobre o tema, no concurso para preleccionador de Economia, na Universidade de Cambridge, em 1907, sendo aprovado, na segunda tentativa, em 1908. O "Tratado das probabilidades", concluído em 1913, foi publicado, apenas, em 1921, devido à primeira grande guerra mundial.

No "A Treatise on Probability", o conhecimento é lógico, tem a ver com a racionalidade das crenças e não com a conjuntura dos fatos, abrangendo a influência das provas sobre as conclusões(Skidelsky,1999). A probabilidade de Keynes, segundo O’Donnel(1990,p.55), é lógica, porque afirma a objectividade ( embora possua uma dimensão subjectiva na escolha das premissas ), nega a quantificação e baseia-se na crença, adoptando Keynes o "racionalismo", em detrimento, do "empirismo"(teoria da frequência ) e do "pragmatismo"(teoria subjectiva) (O’Donnel,1989,pp.20-21).

"Segundo Keynes, dado um conjunto de proposições $\mathbf{h}$ - denominado "evidência "- se o conhecimento deste justifica uma crença racional num outro conjunto de proposições a, diremos que temos uma relação de probabilidades de grau(a) entre a e h. A probabilidade exprime-se por $\mathbf{a} / \mathbf{h}$. A probabilidade a de $\mathbf{p}$ varia com a evidência h"(Nunes,1998, p.37).

A probabilidade, em Keynes, compara as "evidências" favorável e desfavorável de um dado acontecimento, enquanto o "peso do argumento "constitui a quantidade da evidência disponível, cujo aumento, apenas eleva a probabilidade se a nova evidência favorável superar a nova evidência desfavorável (Keynes,CWJMK,VIII,pp77-78): 
Carabelli (1988), entende que Keynes sempre foi "organicista", pois considerava a ontologia do universo muito complexa, para ser entendível pela razão. Bateman (1991), Davis(1991), O’Donnel (1990), entre outros, defendem que Keynes manteve a posição "atomista", em toda a sua obra. Lawson (1987), Rotheim (1988), Gerrard (1992) e a maioria dos autores que interpretam a questão, consideram que Keynes era "atomista" no tratado das probabilidades, porque a escolha entre duas acções era permitida, dado o conhecimento do efeito de cada acção sobre o todo; e "organicista" na teoria geral, já que a hipótese atómica não era válida no mundo das relações sociais, passando a trabalhar em termos de incerteza em detrimento da probabilidade.

\section{A PREDOMINÂNCIA MARSHALLIANA NA ECONOMIA DE JOHN MAYNARD KEYNES}

Em 1913, John Maynard Keynes, publica o "Indian Currency and Finance", onde critica a utilização do ouro como principal activo de pagamentos e reservas internacionais. Keynes enunciou uma reforma do sistema monetário internacional, através de um "Gold Exchange standard", em que a liquidez deveria ser composta por ouro e por outras moedas de conversibilidade internacional, isto é, um padrão fiduciário internacional, em que as moedas conversíveis em ouro e administradas pelos bancos centrais nacionais, constituíssem o volume de reservas internacionais (Keynes,CWJMK,I,p.182).

O "Gold Exchange standard", visava tornar mais elástica a liquidez internacional, necessária para elevar os volumes de comércio e produção mundial. A política monetária seria mais activa para estabilizar os níveis de preços e revitalizar a renda e o emprego, uma vez que, no padrão-ouro, a política monetária era passiva, já que a oferta de moeda nacional ( e por inerência, as taxas de juros), dependia de entradas e saídas de reservas internacionais, a saber, o ouro. Por outro lado, Keynes criticava o mecanicismo de ajustamento automático do balanço de pagamentos do regime padrão ouro, pois, em um contexto de escassez do ouro, impunha um ajustamento deflacionário e recessivo sobre a economia do pais (Filho, 2006).

$\mathrm{Na}$ tradição marshalliana, Keynes, nesta altura, defendia o liberalismo comercial e a livre circulação de capitais, porém, apesar da sugestão do "Gold Exchange standard”, propõe um regime de câmbio fixo administrado, 
para dar maior liberdade à política monetária, inexistente no padrão ouro.

Apesar de toda a sua discussão de inovação na prática monetária, aceitava, que num mundo onde vigorava o padrão ouro, as taxas de câmbio fixas eram imprescindíveis para o ajuste automático dos balanços de pagamentos, através dos fluxos de capital internacional de curto prazo (Moggridge(1976)(1986)).

Por outro lado, Keynes aceitava a teoria quantitativa da moeda, segundo a qual, dada a estabilidade da demanda da moeda e da produção, o nível de preços é directamente proporcional à quantidade de moeda oferecida, tornando a estabilização dos preços ilusoriamente fácil. Vigorava a neutralidade monetária, a moeda desempenhava, apenas, a função de meio de troca, não influenciando as variáveis reais da economia, mas somente as variáveis monetárias.

Após a primeira grande guerra mundial, Keynes compareceu na Conferência de Paz de Paris (1919), na qualidade de representante do tesouro inglês. Os gastos do governo inglês, durante o conflito armado, tinham aumentado o nível de preços e reduzido o poder de compra dos trabalhadores. Em 1916, Keynes propôs, ao governo de Mckenna, o aumento dos impostos, que não poderiam ser excessivos, dai a dependência dos empréstimos americanos (Dimsdale,1977). Os EUA queriam que os seus adiantamentos fossem gastos na compra de seus produtos, em vez de usados para estabilizar a libra. A Grã -Bretanha também tinha feito diversos empréstimos aos aliados.

Em Outubro de 1918, Keynes sugere um pagamento de reparações da Alemanha no valor de 1 bilhão de libras. Contudo, em Dezembro de 1918, a Comissão, constituída pelo gabinete de guerra, sugeriu ao governo inglês que a Alemanha pagasse 24 bilhões de libras(Elcock, 1977). Quando da abertura da conferência, Keynes solicitou que a Inglaterra propusesse aos EUA o cancelamento dos débitos interaliados. Dada a falta de consenso, Keynes propôs que o valor a pagar pela Alemanha, durante os seguintes 30 anos, fosse decidido mais tarde. Descontente com as exigências feitas à Alemanha, deixou o governo, em Junho de 1919.

Em 1919, Keynes escreveu "The Economic Consequences of the Peace", onde propõe a redução das reparações de guerra da Alemanha, remetidas apenas para a França e Bélgica, e o cancelamento das dividas entre os aliados. Segundo ele, a crise monetária advinha das emissões de moeda 
dos governos para compensar os deficits fiscais, enquanto o desemprego, derivava de deficits do balanço de pagamentos e de politicas proteccionistas nacionais. Pediu a criação de uma União de livre comércio, para aumentar o comércio mundial e diminuir a inflação. Na senda da teoria quantitativa da moeda, para controlar a inflação, exige um controle rígido dos meios de pagamentos. Apesar do seu comprometimento com o capitalismo do laissez-faire, deixa implícito a necessidade de regulação do capitalismo, pois a guerra tinha "destruído" o padrão ouro e as moedas flutuavam livremente(Keynes,CMJMK,II).

Entende que a política cambial deveria se adequar à política monetária, dada a importância desta, na estabilidade de preços. Após a guerra, os bens manufacturados europeus "compravam" menos alimentos e matériasprimas, logo, em 1922, argumenta a favor da desvalorização das moedas europeias face ao dólar(Skidelsky,1999).

Os alemães pagaram as reparações, através de empréstimos, até 1929, o que levou à hiperinflação. Depois, a partir de 1945, retomaram os pagamentos. No final de 1922, Keynes foi convidado, pelo governo alemão, para uma conferência, onde insistiu na fixação da taxa de câmbio alemã e na suspensão das reparações para eliminar a hiperinflação, pois tal equilibraria as contas publicas e externas, dada a existência de consideráveis reservas internacionais ( Batista jr, 1999). Em 1922, publica "A Revision of the treaty", onde reafirma as principais ideias, contidas no livro de 1919(Keynes, CWJMK,III).

Em 1922, em "The Stabilisation of the European Exchanges: a Plan for Genoa", Keynes, defende o retorno da Inglaterra ao Padrão-ouro, mas não à paridade vigente em 1914, sugerindo um regime cambial do tipo "Crawling Peg”, em que a taxa de câmbio pudesse variar 5\%, em torno de uma banda cambial estabelecida (Keynes,CWJMK,XVII,pp.355-369).

No “A Tract on Monetary Reform”, publicado em 1923, Keynes analisa a influência das variações no valor da moeda na natureza distributiva e produtiva da economia, concluindo que a deflação, por agravar o desemprego, é pior que a inflação, apesar da injustiça desta(Keynes,CWJMK,IV,p.3). Preconizava que a especulação e o desemprego na economia decorriam da instabilidade monetária, logo, seguindo a teoria quantitativa da moeda, entendia que a estabilidade de preços devia ser o principal objectivo da política económica, 
em particular da política monetária, de forma a "controlar" as expectativas dos empresários e, assim, diminuir os efeitos negativos sobre a produção e o emprego (Keynes,CWJMK,IV,pp.34 e 116). No livro, manifesta-se contra o retorno ao Padrão ouro, pois deveriam existir taxas de câmbio ajustáveis ao nível de preços interno, considerado estável, de forma a "gerir" as expectativas dos agentes económicos, tendo em vista um nível "normal" de emprego. Logo, era a política cambial que deveria estar vinculada à dinâmica da política monetária de estabilização de preços. "Quando a estabilidade do nível de preços interno e a estabilidade da taxa de câmbio são incompatíveis, a primeira é geralmente preferível" (Keynes,CWJMK,IV,p.132).

Em "A Tract on Monetary Reform”, Keynes reformula a "equação quantitativa de Cambridge": $\mathbf{n}=\mathbf{p}(\mathbf{k}+\mathbf{k}$ '. $\mathbf{r})$, em que $\mathbf{n}$ é a oferta da moeda, p é o nível geral de preços, $\mathbf{k}$ é a demanda de moeda em poder do publico, $\mathbf{k}^{\prime}$ é a demanda de moeda em termos de moeda bancária e $\mathbf{r}$ é a razão (reservas bancárias/Depósitos à vista). Keynes conclui que, no curto prazo, não vigora a teoria quantitativa da moeda, pois os hábitos do publico em demandar moeda e o comportamento do sistema bancário em alterar $\mathbf{r}$, afectavam a quantidade total de moeda na economia $\mathbf{n}$ e o nível de preços $\mathbf{p}$, desfazendo a proporcionalidade entre $\mathbf{n}$ e $\mathbf{p}$, e acentuando a relevância da política monetária, para a estabilidade da economia (Keynes,CWJMK,IV,pp.65-69). Keynes, idealizava uma administração discricionária, rejeitando o estabelecimento de "regras" para a oferta de moeda (Skidelsky,1999); sendo favorável à regulação do sistema monetário internacional.

Em Abril de 1925, Winston Churchill, ministro das finanças inglês, restabeleceu o Padrão ouro à paridade de 1914, isto é, US\$4,86 por libra, e não ao câmbio vigente de US $\$ 4,4 \mathrm{O}$ por libra. Keynes ripostou em "The Economic consequences of Mr Churchill", alertando que a sobrevalorização da libra em $10 \%$, reduziria as exportações e o emprego, e a diminuição do preço das importações levaria à deflação ( de preços e salários) interna. Logo, ciente que as politicas monetária( devido á taxa de câmbio fixa ) e salarial (força dos sindicatos ) não resolveriam os desequilíbrios internos e externos da economia inglesa, passou a advogar politicas proteccionistas, como instrumento de política económica e o abandono da Inglaterra, de uma vez por todas, do Padrão ouro (Keynes,CWJMK,IX,pp.207-230). 


\section{TRANSIÇÃO NA VISÃO ECONÓMICA DE JOHN MAYNARD KEYNES}

De 1925, ao fim do Padrão ouro, em 1931, a Inglaterra sofreu um período de crise, com desemprego e deflação. As ideias e proposições de Keynes modificam-se. Inicialmente, sofreu influências de Robertson(1926), que alerta para a distinção entre decisões de poupar e decisões de investir. Depois, aperfeiçoa, a visão de um livro de Knut Wicksell(1936), escrito em 1898, que refere, devido ao padrão ouro, a impossibilidade da taxa de juro de mercado se ajustar à taxa de juros "natural"( que sobre os empréstimos seria neutra em relação aos preços das mercadorias).

Em 1930, John Maynard Keynes, publica" A Treatise on Money", onde define três tipos de depósitos: de "renda", que se referem ao rendimento pessoal dos indivíduos; "comerciais", atinentes ao capital de circulação produtiva das empresas; de "poupança", retido como investimento devido ao retorno esperado em juros. Depois, descreve dois circuitos de circulação monetária: "Circulação industrial ", onde a moeda dá suporte à circulação de bens e serviços produzidos na economia, funcionando, de acordo com a teoria quantitativa da moeda, como meio de troca; "Circulação financeira", em que a moeda é canalizada para a actividade especulativa( acções, títulos da divida,etc), não relacionadas à deslocação de renda corrente, funcionando a moeda, como um activo.

No capítulo dez, define as "equações fundamentais "num referencial teórico da teoria quantitativa da moeda marsahalliana, onde caracteriza os movimentos cíclicos da produção. Quando os custos de produção igualam os preços de venda, os lucros são nulos, e a poupança e o investimento equivalem-se. Se os preços de vendas superam os custos de produção, ocorrem ganhos e a poupança é superada pelo investimento, existindo uma produção acima do pleno emprego, e inflação. Enquanto, se os custos de produção subjugarem os preços de vendas, a poupança excederá o investimento o que levará ao desemprego e à deflação, a não ser que melhorasse a rentabilidade do investimento e/ou baixasse a taxa de juros (Keynes,CMJMK,V,p.121 ). Logo, o foco continuava nas variações do nível de preços e não da produção e/ou do emprego.

Para Keynes, uma queda na taxa de juros, melhoraria as expectativas dos agentes económicos, o que "transportaria" a moeda da circulação finan- 
ceira para a circulação industrial, elevando o investimento e, finalmente, a produção. A partir daqui, Keynes caracteriza dois tipos de agentes económicos, nos mercados financeiros: os "Bull”, que são optimistas e esperam uma queda na taxa de juros, logo reduzem o entesouramento, ajudando à expansão da economia; os" Bear", que são pessimistas e apostam na alta da taxa de juros, retendo a moeda, levando a economia à depressão. Já aqui, as ideias da preferência pela liquidez; da moeda como um activo; da não neutralidade da moeda bem como do facto de ser o lucro que "move" as empresas, estão presentes.

No Tratado da moeda, visando uma maior autonomia das politicas económicas nacionais, propõe um regime cambial, tipo "crawling peg", em que a partir de uma taxa fixa, cada país pudesse variar, a sua moeda em relação ao ouro, em 2\% (Filho,2008). Tal regime seria administrado por um banco central internacional, que manteria o padrão monetário estável em relação ao preço de 62 mercadorias, que circulassem no mercado internacional.( Keynes,CWJMK,VI,pp.351-352).

No Padrão ouro, as politicas monetária ( queda da taxa de juro) e cambial (desvalorização) não poderiam ser utilizadas, para resolver o hiato entre o investimento e a poupança, e, assim, eliminar o desemprego e a deflação. A redução salarial era um processo ruinoso, do ponto de vista social. Logo, propõe, em 1929, no artigo com Hubert Henderson," Can Llody George do it ?'( Keynes,CWJMK,IX,Cap.9), e, em 1931, no relatório final da Comissão MacMillan, a adopção do "caso especial" do Tratado da moeda, isto é, investimentos públicos, mesmo que financiados por empréstimos internacionais, para tirar a Grã-Bretanha da recessão, alicerçando pela primeira vez, a defesa do seu ponto de vista, na teoria do multiplicador de Richard Kahn(1931). No Tratado da moeda(1930), o caso geral, era concentrar a política monetária nas taxas de juros de longo prazo e no ajustamento do suprimento de crédito às necessidades variáveis da economia (Moggridge, 1976).

Mas Keynes sabia que o investimento publico elevaria o emprego e o rendimento, acarretando o aumento das importações, pelo que, passou a defender medidas proteccionistas; como subsídios às exportações e a adopção de tarifas às importações, para proteger o emprego doméstico e reduzir o desequilíbrio externo. Em Março de 1931, no "Proposal for a 
revenue tariff" (Keynes,CWJMK,IX,pp.231-238) propôs tarifas de 15\% às importações de produtos manufacturados e $5 \%$ às importações de matérias-primas e alimentos.

\section{AS PROPOSIÇÕES TEÓRICAS INOVADORAS DA TEORIA GERAL}

Em Setembro de 1931, a Inglaterra abandonou o Padrão-ouro, e Keynes negligenciou a política comercial (retirando as suas propostas proteccionistas), considerando as politicas monetária e cambial responsáveis pela dinâmica da produção e emprego. Para Keynes, o "caso especial", em que a produção não estava ao nível do pleno emprego, tornou-se a situação geral, passando a dar mais atenção às mudanças no produto, em detrimento das variações dos preços. Em 1933, em "The Means to prosperity" (Keynes,CWJMK,IX,pp.335-366), voltou a advogar "obras publicas" para solucionar a crise, e uma política proteccionista, para industrias menos dinâmicas, como o aço e a agricultura, para proteger o emprego, que confirmaria em"Pross and Cons of Tariffs" (Keynes,CWJMK,XXI,pp.204-210).

Richard Kahn(1931), percebeu que as equações fundamentais, do tratado da moeda(1930), eram um caso especial, dada a inelasticidade da produção face a alterações na procura, numa altura, em que a Inglaterra estava em crise (longe do pleno emprego). Logo, John Maynard Keynes, na "The General Theory of Employment, Interest and Money" de 1936, centralizou a análise, nas mudanças da produção e do emprego, vigorando a teoria quantitativa da moeda, apenas, no "caso especial", em que a economia estivesse no pleno emprego." Enquanto houver o desemprego, o emprego mudará na mesma direcção da quantidade da moeda; e enquanto houver o pleno emprego, os preços mudarão na mesma proporção que a quantidade da moeda" (Keynes,CWJMK,VII,p.296).

$\mathrm{Na}$ “Teoria geral"(1936), Keynes define o principio de demanda efectiva, em que o empresário decide quantos trabalhadores contratar e quanto produzir de acordo com o que espera vender; a partir da confrontação entre a curva da oferta agregada, que indica a renda necessária para o empresário oferecer determinado volume de emprego, e a curva da demanda agregada, que apresenta a renda que o empresário espera receber por oferecer de- 
terminado volume de emprego. O nível de emprego, será determinado no ponto de intersecção entre as duas curvas, onde se estabelece a produção e, portanto, a "demanda efectiva"(Lopes e Vasconcellos org., 2000, p.114). Logo, abaixo do pleno emprego, não adianta baixar os salários nominais, se os empresários não vislumbram lucro, na produção adicional. Se a demanda agregada for inferior à oferta agregada, então a produção e o emprego devem baixar, para se restabelecer a igualdade." O sistema económico pode estar em equilíbrio estável ... a um nível abaixo do pleno emprego"(Keyn es,CWJMK,VII,p.30).

$\mathrm{Na}$ teoria de determinação do investimento de Keynes, a Eficiência marginal do capital é a taxa de desconto que iguala o fluxo de receita esperada ao custo de investimento. Se esta taxa for superior à taxa de juros que representa o custo de se obter empréstimos para realizar o investimento, o empresário investe, senão, não investe. Ao contrário da estabilidade do consumo, o investimento é instável dada a precariedade de formação de expectativas, num ambiente de incerteza, dos empresários. Para estabilizar a economia, Keynes propõe o aumento da despesa publica para compensar a menor despesa privada, em face de um menor investimento privado (Lopes e Vasconcellos (org.),2000,p.115).

Face à incerteza do futuro, os agentes preferem guardar moeda na forma não reprodutível, em vez de utilizá-la para aquisição de bens produzidos pelo trabalho, logo as decisões de gasto(consumo e investimento) são adiadas para um futuro menos incerto. A preferência pela liquidez, face à ausência de um calculo probabilístico sobre o futuro, leva à diminuição da demanda efectiva e, portanto, da produção e do emprego, porque a moeda tem a função de reserva de valor, verificando-se a não neutralidade da moeda. $\mathrm{Na}$ Teoria geral, a taxa de juros, é um fenómeno eminentemente monetário, determinado pela igualdade entre demanda de moeda e oferta de moeda. A taxa de juro é o preço que guia a escolha entre as formas liquida e ilíquida de riqueza (Davidson(1972)(1982)). Na obra de 1936, Keynes considera a oferta de moeda exógena, isto é, sobre o comando absoluto das autoridades monetárias, embora em" A Treatise on money"(1930), reconheça a acomodação da oferta da moeda, por parte do sistema bancário (Fiocca,2000).

Neste trabalho de 1936, Keynes enfatizou três motivos pelos quais as pessoas procuram moeda. O motivo transacção, que depende do montante 
do rendimento e das compras projectadas e hábitos de pagamentos dos agentes. No motivo de precaução, as pessoas retêm moeda para atender às contingências inesperadas e às oportunidades imprevistas na realização de negócios vantajosos, e, portanto, transportam moeda de um período de rendimento para outro, dependendo das incertezas em relação ao futuro. $\mathrm{O}$ motivo de especulação, onde a demanda especulativa de moeda, está relacionada com as expectativas especificas com respeito ao comportamento futuro da taxa de juros.

Para solucionar a crise da demanda efectiva, e dada a descrença de Keynes, na política monetária de baixas taxas de juros e na flexibilidade dos salários nominais, impõe-se a intervenção do Estado em termos de actividade produtiva e de politicas publicas (Keynes,CWJMK,XXI,pp.59-60).

"Uma outra característica do método de Keynes deve ser sublinhada: abjura o raciocínio típico do equilíbrio geral Walrasiano em favor do encadeamento lógico das causações. A sequência seguinte é típica de A Teoria geral: dada a propensão a consumir, o volume de emprego é determinado pelo montante do investimento; dada a rentabilidade esperada do investimento, seu montante é determinado pela taxa de juros; dada a quantidade da moeda, a taxa de juros é determinada pela preferência pela liquidez" (Skidelsky,1999,pp.59-60).

A partir da Teoria geral, os Pós-Keynesianos descrevem alguns tópicos da economia de Keynes: os contratos são expressos em unidades monetárias ; não existe neutralidade da moeda no curto e no longo termo; existe um tempo histórico onde as decisões são tomadas de forma irreversível; o futuro é incerto; a economia não tende para um equilíbrio estável (Davidson,1994).

Em 1931, Keynes publicou "Essays in Persuasion", um trabalho de carácter político e filosófico, em que defende suas novas proposições teóricas. Keynes era um intervencionista, e as implicações politicas de seu pensamento económicos são inequivocamente, favoráveis a uma política económica activa." Essays in Persuasion", está dividido em seis partes, sobre seis temas: tratado da paz; inflação e deflação; volta ao padrão ouro; carácter político; relativo ao futuro; últimos ensaios, dos quais, alguns textos, já foram citados, neste trabalho (Keynes,CWJMK,IX).

Em 1933, em "Essays in Biography", com alguns capítulos, também, já referenciados, neste texto, Keynes, faz alguns comentários sobre onze 
figuras politicas do seu tempo; elabora nove ensaios biográficos sobre a vida de nove grandes economistas; documenta alguns esboços biográficos de amigos particulares e, por fim, analisa as obras de Newton e Einstein (Keynes, CWJMK,X).

\section{A APLICAÇÃO PRÁtiCA DA ECONOMIA DE JOHN MAYNARD KEYNES}

Com a Segunda grande guerra mundial, Keynes procurou uma solução que permitisse financiar as despesas de guerra da Grã-Bretanha e, ao mesmo tempo, controlar a inflação, do excesso de demanda agregada. Em 1939, escreve "How to Pay for the war", onde apresenta quatro soluções: poupança voluntária, inflação; impostos e poupança compulsória. Tanto a inflação, quanto a aplicação de impostos adicionais eram injustas, enquanto os valores oriundos das poupanças voluntárias seriam insuficientes. Dai a sugestão de uma poupança compulsória, retida durante a guerra e devolvida posteriormente (Keynes,CMJMK,IX,p.379).

Diferentemente dos impostos e da inflação, no final da guerra, os trabalhadores seriam ressarcidos, e receberiam o valor recolhido. A natureza redistributiva do plano, alicerçava-se no facto, de que no final da guerra, seria cobrado um imposto sobre o capital, por sugestão de F.Hayek, para restituir as poupanças compulsórias aos trabalhadores. Para além disso, as famílias de menor rendimento ficariam isentas; os bens de primeira necessidade, manteriam o seu valor real. Os cidadãos com maiores rendimentos, pagariam mais impostos, em termos relativos. Por outro lado, pode-se dizer, que "How to Pay for the War", foi a primeira aplicação prática, da economia de Keynes, ao refrear a economia durante a guerra (numa situação de pleno emprego), e ao expandir a economia, com o pagamento aos trabalhadores, após a guerra, num primeiro período de recessão que ocorresse (Keynes,CWJMK,XXII,p.123).

Em "Proposal for an International Clearing Union"de 1943, Keynes apresentou propostas para reformar o sistema monetário internacional. Defende, a criação de um banco central internacional que emitiria a moeda de reserva internacional(bancor), com o objectivo de: proporcionar a liquidez necessária à expansão da produção e comércio internacional; apresentar os 
recursos necessários para os ajustamentos, de curto prazo, dos balanços de pagamentos das economias. Ao contrário do padrão ouro, o esforço do ajuste externo, caberia, também, aos países superavitários, e, não só, aos países deficitários, através de uma variação máxima, de $5 \%$, das suas moedas em relação à paridade fixa ( Keynes,CWJMK,XXV,p.190).

O pais deficitário, poderia, depreciar a moeda; controlar os movimentos de capitais; reduzir as reservas internacionais; impor tarifas e fornecer subsídios às exportações. O pais superavitário, poderia, estimular a demanda interna, apreciar a moeda; reduzir as barreiras às importações e fazer empréstimos internacionais aos países deficitários, mas não poderia entesourar a moeda (Keynes,CWJMK,XXV,p.188).

A moeda de reserva internacional, emitida pelo banco central mundial, não era passível de entesouramento (preferência pela liquidez) pelos agentes económicos, circulando apenas, entre os bancos centrais nacionais, com o intuito de dinamizar as relações comerciais e financeiras entre os países, logo, seria "neutra"(ao contrário da moeda, em economia fechada, na teoria geral), não possibilitando a preferência pela liquidez que acarretasse as crises de insuficiência da demanda efectiva da economia mundial.

\section{CONCLUSÃO}

Observou-se, neste trabalho, a importância das influências filosóficas, sociais e politicas na economia de Keynes, segundo o qual, o economista deve possuir uma rara combinação de atributos, isto é, deve ser matemático, historiador, estadista, filósofo, até certo ponto.

$\mathrm{Na}$ fase inicial, seguindo a tradição marshalliana, Keynes preconizava o liberalismo comercial e a livre circulação de capitais, aceitando a teoria quantitativa da moeda.

Posteriormente, na transição da sua visão económica, apesar da predominância nas variações do nível de preços, as ideias da preferência pela liquidez, da moeda como um activo, da não neutralidade da moeda bem como do facto de ser o lucro que "move "as empresas, já estão presentes.

Na Teoria Geral, "o caso especial"do Tratado da moeda, em que a produção não estava no nível do pleno emprego, torna-se a situação geral, prevalecendo as mudanças na produção, em detrimento das variações nos 
preços. São analisados: o principio da demanda efectiva; a teoria de determinação do investimento (eficiência marginal do capital) e a teoria da taxa de juros ( preferência pela liquidez).

"How to Pay for the War", foi a primeira aplicação prática, da economia de Keynes, ao refrear a economia durante a guerra (numa situação de pleno emprego) e, ao expandir a economia, com o pagamento aos trabalhadores, após a guerra, num primeiro período de recessão que ocorresse (Keynes, CWJMK,XXII,p.123).

Por fim em "Proposal for an International Clearing Union"de 1943, Keynes defendeu a criação de um banco central internacional que emitiria a moeda de reserva internacional (bancor) com o objectivo de: proporcionar a liquidez necessária à expansão da produção e comércio internacional; apresentar os recursos necessários para os ajustamentos, de curto prazo, dos balanços de pagamentos das economias.

\title{
JOHN MYNARD KEYNES' POLITICAL ECONOMY: A SHORT INTRODUCTION
}

\begin{abstract}
The main objective of this article is to analyze the evolution of the ideas and theoretical propositions of the work of John Maynard Keynes. The underlying hypothesis of this work, in a post Keynesian approach, is the defence of change of economic thought of Keynes, a vision marshallian compatible with laissez-faire capitalism, for an innovative theoretical analysis of the problems of capitalism pós-great depression, in the years 1930.
\end{abstract}

Keywords: John Maynard Keynes; General Theory; Post-Keynesian economics.

JEL Classification: B50; E12; E42; E65; F33. 


\section{REFERÊNCIAS}

BATEMAN,B.W.(1991): “The Rules of the Road: Keynes's Theoretical Rational of Public Policy", in: B.W.Bateman e J.B.Davis(org.)Keynes and Philosophy, Edward Elgar, Aldershot, pp.55-68.

BATISTA JR,P.N.(1999):" Keynes e a Estabilização do marco alemão", in: G.T.Lima ; J.Sicsu e L.F. de Paula(org.).Macroeconomia Moderna. Keynes e a Economia Contemporânea, Editora Campus, Rio de Janeiro,pp.340-370.

BURKE,E.(1757): An Inquiry into the Origin Our Ideas of the Sublime and the beautiful, J.Dodsley in Pall mall, London.

CARABELLI,A.(1988): On Keynes's Method, MacMillan, London.

DAVIDSON,P.(1972): Money and Real World, MacMillan, London

DAVIDSON,P.(1982): International Money and The Real World, MacMillan, London.

DAVIDSON,P.(1994): Post Keynesian Macroeconomic Theory, Edward Elgar,Aldershot

DAVIS,J.B.(1991):'Keynes View of Economic as a Moral Science", in : B.W.Bateman e J.B.Davis(org.). Keynes and Philosophy, Edward Elgar, Aldershot, pp. 89-103

DIMSDALE,N.H.(1977):” Keynes e as finanças da primeira guerra mundial", in: M. Keynes(org.). Ensaios sobre John Maynard Keynes, Paz e Terra, Rio de Janeiro, pp.123-144(Essays on John Maynard Keynes, Cambridge University Press, Cambridge, 1975).

ELCOCK,H.(1977): “J.M.Keynes na Conferência de Paz de Paris “, in M.Keynes(org.). Ensaios sobre John Maynard Keynes, Paz e Terra, Rio de Janeiro, pp. 145-159(Essays on John Maynard Keynes, Cambridge University Press, Cambridge,1975). 
FILHO,F.F.(2006): Politica Comercial, Taxa de câmbio, Moeda Internacional. Uma análise a partir de Keynes. Editora da UFRGS. Porto Alegre.

FILHO,F.F.(2008): "Câmbio controlado e controle de capitais para países emergentes: uma análise a partir de Keynes", in: J.Sicsu e C.Vidotto(org.). Economia do Desenvolvimento. Teorias e Politicas Keynesianas, Editora Campus, Rio de Janeiro,pp.106-117.

FIOCCA, D.(2000): Oferta de Moeda na Macroeconomia Keynesiana. Paz e Terra, São Paulo.

GERRARD,B.(1992):"'From A Treatise on Probability to the General Theory: continuity or change in Keynes's thought?", in: B.Gerrard e J.Hillard. The Philosophy and Economics of J.M.keynes, Billing and Sons, Worcester, pp.80-95.

HARROD,R.F.(1951): The Life of John Maynard Keynes, W.W. Norton \& Company, London.

KAHN,R.F.(1931):" The Relations of Home Investment to Unemployment". Economic Journal, no 41, pp.173-198.

KEYNES,J.M.(1971-a): Indian Currency and Finance, MacMillan, London( The Collected Writings of John Maynard Keynes, Vol. I ).

KEYNES,J.M.(1971-b): The Economic Consequence of the Peace, MacMillan, London ( The Collected Writings of John Maynard Keynes, Vol. II ).

KEYNES,J.M.(1971-c): A Revision of the Treaty, MacMillan, London( The Collected Writings of John Maynard Keynes, Vol. III).

KEYNES,J.M.(1971-d): A Tract on Monetary Reform, Macmillan, London( The Collected Writings of John Maynard Keynes, Vol. IV).

KEYNES,J.M.(1971-e): A Treatise on Money: I. The Pure Theory of Money, Macmillan, London ( The Collected Writings of John Maynard Keynes, Vol. V) 
A economia de John Maynard Keynes: uma pequena introdução

KEYNES,J.M.(1971-f): A Treatise on Money: II. The Applied Theory of Money, MacMillan, London (The Collected Writings of John Maynard Keynes, Vol. VI).

KEYNES,J.M.(1973-a): The General Theory of Employment, Interest and Money, MacMillan, London (The Collected Writings of John Maynard Keynes, Vol. VII)

KEYNES,J.M.(1973-b): A Treatise on Probability, MacMillan, London (The Collected Writings of John Maynard Keynes, Vol. VIII).

KEYNES,J.M.(1972-a): Essays in Persuasion, Macmillan, London( The Collected Writings of john Maynard Keynes, Vol. IX).

KEYNES,J.M.(1972-b): Essays in Biography, MacMillan, London( The Collected Writings of John Maynard Keynes, Vol. X).

KEYNES,J.M.(1973-c): The General Theory and After- Part II- Defence and Development, MacMillan, London ( The Collected Writings of John Maynard Keynes, Vol. XIV, edited by Donald Moggridge.).

KEYNES,J.M.(1977): Activities 1920-22: Treaty Revision and Reconstruction. MacMillan, London( The Collected Writings of john Maynard Keynes, Vol. XVII, edited by Elizabeth Johnson).

KEYNES, J.M.(1982): Activities 1931-39: World Crises and Policies in Britain and America. Macmillan, London ( The Collected Writings of John Maynard Keynes, Vol. XXI, edited by Donald Moggridge).

KEYNES,J.M.(1978): Activities 1939-45: Internal War Finance. MacMillan, London ( The Collected Writings of John Maynard Keynes, Vol. XXII, edited by Donald Moggridge).

KEYNES,J.M.(1980): Activities 1940-44: Shaping the Post-War World. The Clearing Union, MacMilan, London ( The Collected Writings of John Maynard Keynes, Vol. XXV, edited by Donald Moggridge). 
LAWSON,T.(1987): "The Relative/ Absolute Nature of knowledge and Economic Analysis”. Economic Journal,n 97, December.

LOPES, L.M.; VASCONCELLOS,M.A.(org.)(2000): Manual de Macroeconomia, Editora Atlas, São Paulo.

MOGGRIDGE,D.E(1976): Keynes, MacMillan, London.

MOGGRIDGE,D.E.(1986): "Keynes and the International Monetary System 1909-46" in : J.Cohen e G.Harcourt (org.).International Monetary Problems and Supply Side Economics: Essays in honour of Lorie Tarshis, St.Martin's Press, New York, pp.56-83.

MOORE,G.(1903): Principia Ethica, Cambridge University Press, Cambridge.

NUNES,M.J.(1998): O Pensamento de Keynes. Aspectos epistemológicos e metodológicos. Imprensa Nacional -Casa da Moeda, Lisboa.

O’DONNEL,R.(1989): Keynes: Philosophy, Economics and Politics, Macmillan, London.

O’DONNEL,R.(1990): "Continuity in Keynes Conceptions of Probability”, Perspectives on the History of Economic Thought, Vol. IV, Selected papers from the History of Economic Society Conference, 1988, edited by Moggride, D., pp.53-72.

ROBERTSON,D.H.(1926): Banking Policy and Price level. P.S.kIng \& Sons. London.

ROBINSON,A.(1947) : “John Maynard Keynes, 1883-1946”, Economic Journal, March.

ROTHEIM,R.(1988): "Keynes and the Language of Probability and uncertainy", Journal of Post-Keynesian Economics, $n^{\circ} 1$, pp.82-99. 
A economia de John Maynard Keynes: uma pequena introdução

SKIDELSKY,R.(1999): Keynes. Jorge Zahar Editor, Rio de Janeiro ( Keynes, Oxford University Press, Oxford, 1996):

WICKSELL,K.(1936): Interest and Prices. MacMillan. London.

Artigo submetido em abril de 2011 e aceito para publicação em junho de 2011. 